\title{
Risking Death for Survival: Peasant Responses to Hunger and HIV/AIDS in Malawi*
}

\author{
Deborah Fahy Bryceson $\&$ Jodie Fonseca ${ }^{+}$
}

Beginning in 2001, smallholder peasant households in Malawi faced two life-threatening risks: AIDS and famine. Malawi registers the $8^{\text {th }}$ highest HIV/AIDS prevalence in the world (UNAIDS 2004) and is one of the continent's least urbanized countries with 85 per cent of the national population living in rural areas. Much of the countryside has a reputation for being 'deep rural' in the sense that it is characterized by a patchy road network and poor physical, economic and social infrastructure within a culturally conservative context of village-based traditional tribal leadership. Between 2001 and 2003 the countryside experienced widespread hunger. Speculation about possible links between HIV/AIDS and famine inevitably ensued.

De Waal and Whiteside (2003) argues that a 'new variant famine' surfaced in the context of a rural population predisposed to food insecurity by the prevalence of AIDS morbidity and mortality. It would be impossible to conclusively prove or disprove this thesis. Certainly, the deteriorating welfare status of the Malawian rural population amidst the rising prevalence of HIV/AIDS prior to the famine can be amply demonstrated (e.g. Ngwira, Bota and Loevinsohn 2001, Frankenberger, Luther, Fox and Mazzeo 2003). This paper explores the interacting effects of HIV/AIDS and famine. Based on key informant interviews, focus group discussions and a random survey of 141 households in three villages as part of a CARE International study carried out in Lilongwe rural district, Central Province between December 2003 and March 2004. Villagers' coping strategies and social responses under the combined duress of HIV/AIDS and famine are highlighted.

The spread of AIDS in Africa has generally been associated with political upheaval and geographical mobility. For some time, rural farming populations were considered relatively 'safe', tucked away from harm. The differential between rural and urban HIV prevalence seemed to confirm this view. However, in Malawi the gap between high urban and low rural HIV prevalence is now closing despite the 'deep rural' image of the countryside. As the AIDS pandemic widens and deepens, the changing vulnerability profile suggests that rather than asking what processes are responsible for its spread, we need to ask who is most vulnerable and why. The issue of agency within specific modes of livelihood contexts begs attention. Some of the proliferating literature on AIDS now hints at the need to consider HIV as an 'occupational hazard' for particular economic categories of people. This hazard may not accord with intuitive reasoning. Campbell's (2003) comparison of South African miners, youth and prostitutes discovered that prostitutes were in fact the least vulnerable to HIV infection because of their professional insistence on using condoms, unlike the youth and miners who adopted a macho 'devil-may-care' attitude towards unprotected sex. Allison and Seeley (2004) document similar attitudes amongst the Kenyan fishermen whose hyper-macho group identity, nocturnal absences from home and mobility subjected them to high HIV exposure. This paper is focussed on the agency of another livelihood category, which broadly constitutes a social class at the very centre of Malawi's political economy namely, the smallholder peasant farming population. We

\footnotetext{
* Paper presented at the International Conference on HIV/AIDS, Food and Nutrition Security organized by IFPRI in Durban, South Africa, 14-16 April 2005. We are grateful to CARE International and the Regional Network on HIV/AIDS, Rural Livelihoods and Food Security (RENEWAL) who sponsored the study upon which this paper is based. Special thanks go to the CARE Malawi staff and John Kadzandira of the University of Malawi for their contribution to the data collection.

Deborah Fahy Bryceson, African Studies Centre, Leiden University (email: dfbryceson@bryceson.net)

${ }^{+}$Jodie Fonseca, CARE International, Washington DC (email: jfonseca@care.org)
} 
turn first to a consideration of the material context of their risk-taking behavior before considering their response vis-à-vis famine and HIV/AIDS.

\section{Sons and Daughters of the Soil}

Malawian rural farmers, at first glance, appear to conform to all the defining characteristics of peasantries classically through history, notably: farming is their major occupation encompassing both subsistence and commodity production. The family serves as their main production and consumption unit. They constitute a subordinate class vis-à-vis state power and market channels facing adverse market conditions and intense poverty, and their village communities are relatively isolated, poorly serviced and inward-looking (Bryceson 2000). Yet, Malawi's peasant household production units have, for many decades, not been strictly agrarian or self-sufficient in food production. Within Malawian peasant households, physical separation of family members became a norm due to male labor migration.

Both colonial and Banda's post-colonial government gave priority to plantation estates of tea and tobacco as opposed to smallholder household production, leaving peasant households to be based primarily on subsistence production and migrant labor to Malawi's plantations in the first instance, but also further afield to the mines of South Africa and other employment activities elsewhere in Southern and East Africa. Thus, the household farm unit, left in the care of women and older men, was directed at subsistence food production supplemented by cash remittances of male migrants. Lack of government attention to food crops and to extension for women farmers, combined with women's lack of cash for agricultural input purchase, has left Malawi with the legacy of 'female farming' of subsistence food crops (Boserup 1970, Bryceson 1995), as well as extremely low levels of agricultural productivity relative to neighboring countries (Ellis 2003).

More recently, in the post-Banda 1990s, the liberalization of burley tobacco production in the 1990s did, however, give better-off Malawian smallholder households with comparatively more land, the opportunity to start producing a cash crop (Peters 1996, Ellis et al. 2003). The national government attempted to boost maize yields by introducing semi-flint hybrids, but under the structural adjustment programme, the fertilizer subsidy was retracted in 1994, a move that local people continue to deeply resent (Frankenberger et al. 2003). Over the elapse of many years, the plurality of the country's food crops was displaced by an over-reliance on maize - a risk to national as well as household food security. Recent estimates indicate roughly 55 percent of smallholder farmers have less than one hectare of cultivable land and are incapable of producing all of their staple food needs (Malawi 2002). Male labor migration opportunities have been largely eliminated to destinations in Southern Africa due to the changing political and economic situation in the region, while plantation wage labor in Malawi has also been in decline. Meanwhile, Malawi's smallholder tobacco production stagnated (Frankenberger et al. 2003).

Peasants are often equated with rustic subsistence farmers, which distorts their historical role as subsistence and commodity producer who are part and parcel of world economic, political and cultural trends, but from a marginal subordinate position. Located at the far end of vertical marketing chains, they are price-takers in the world market. Worldwide, peasants have tended to fall under the influence of the world's hegemonic religions and this is certainly the case in Malawi where Scottish Presbyterian missionaries as well as many other Christian faiths proselytized. However, local native authorities and strong tribal identities mediated these religious influences.

In the post-independence period, several African heads of state chose to dismantle the colonial native authority local governance structure that kept power in the hands of traditional ethnic leaders such as chiefs and lineage heads. Banda, however, continued to rely on tribal authorities and lineage heads. Local rule in the countryside retained a conservative traditionalist outlook.

Malawian villages can be considered remote and insulated in several respects. The traditional authorities at village level are usually male elders who rarely have much formal education and are not subject to democratic election. Furthermore, people generally have a restricted local outlook and horizon. A person's property rights and welfare are largely determined by maintaining contact and good relations with cognatic relations in his or her birth locality. Traditionalism is reinforced by the generally low level of schooling of the rural adult population, the legacy of the very late introduction of universal primary education in 1994 following Banda's departure from the Presidency. Lack of investment in rural areas during Banda's long presidential reign resulted in a rural peasantry markedly 
disadvantaged in terms of education, health and agricultural productive services compared with neighboring countries. Rural road building was not a priority and rural markets were constrained by parastatal market controls. It is within this economic and cultural milieu that the 2001-2002 famine hit.

\section{Famine Response}

Malawian peasants' food security is subject to marked year-to-year fluctuation of rainfed agriculture. ${ }^{1}$ In fact, a bumper harvest preceded the poor harvest and severe food shortages and famine that occurred in 2001-02. Some commentators have remarked that the famine was out of proportion to the level of the harvest shortfall, arguing that ADMARC's ill-timed decision to export grain stocks nudged the country towards famine (Bookstein and Lawson 2002, Frankenberger et al. 2003).

Peasant farmers have long been known to follow risk-averse farming practices and prioritize household food self-sufficiency (Allan 1965). Malawian peasants have faced several major famines through the $20^{\text {th }}$ century, notably in $1903,1922,1949$, and 1992 (Frankenberger et al. 2003). Vaughan (1987) documented the coping strategies that occurred during the severe famine of 1949, tracing the narrowing range of options that households had for provisioning themselves with adequate food. Significantly, male migrant laborers' earnings represented a vital support during the 1949 famine. However, she argues that male remittances to matrilineal households were not always very reliable. Men absconded causing widespread destitution of the women and children left behind.

Our survey findings revealed that only 15 percent of households received assistance during the recent famine in the form of food from extended family and only 19 percent accessed food aid from external agencies. The vast majority of households had to fend for themselves. Unlike the 1949 famine, during the 2001-02 famine the cushioning effect of migrant labor was largely absent. Those who had offspring in urban areas had some recourse but, in a country with an extremely low level of urbanization, this did not apply to most rural households. Ganyu labor was their vital coping strategy.

Ganyu has been the main form of inter-household labor exchange between peasant households through much of the $20^{\text {th }}$ century involving the exchange of labor for specified goods or services in kind or for cash (Englund 1999). In some cases, it simply is a mechanism whereby a labor-short household of any wealth-standing can gain access to additional labor seasonally, but generally, it is associated with people from poorer households seeking goods or cash from better-off households through the sale of their labor. Ganyu labor intensifies during peak agricultural seasons and involves the poor casual wage laborer diverting work effort from his/her own fields to that of someone far better off. So too oral interviews suggest that the more balanced reciprocity of ganyu contracts between labor contractor and laborer with family ties degrades under the protracted stress of hunger and ganyu remuneration levels generally decline as was evident during the 1992 famine (Peters 1996).

The search for alternative off-farm income-earning amongst peasant farmers elsewhere in SubSaharan Africa has been cushioned by the household subsistence fallback. In Malawi, a large proportion of rural households have no semblance of a reliable subsistence fallback. They have increasingly been forced to operate with the shortest of time horizons, seeking to provision their needs one day at a time.

We rely on ganyu and cannot carry out income-generating activities because we have no capital since the little we earn from ganyu must be spent on food. (Women's FGD, Chimponda, 12 March, 2004)

Their ever-growing reliance on off-farm ganyu casual labor to address their immediate food needs has produced the paradoxical situation of idle land and labor within peasant household units of production as observed by Ellis et al. (2003). Besides the increasing reliance on ganyu labor markets

\footnotetext{
${ }^{1}$ Staple food crop production was relatively good during the early1990s achieving 90 per cent selfsufficiency between 1987-88 and 1991-92. There was a poor harvest year in 1992-93 when only 50 per cent of national cereal supplies were met by domestic supply and 500,000 tons of food aid was received (FAO website 2004). Thereafter domestic staple food supplies became more erratic ranging from 70-90 per cent self-sufficiency
} 
with exceptionally poor bargaining terms, factor markets are appearing in which the local rural people are handicapped by their lack of literacy, numeracy and market savvy. To date these factor markets are not well-documented in the Malawian agrarian literature. Ellis et al. (2003) notes the growing prevalence of lower-income farmers renting their land to better-off farmers or outsiders. Our interviews and survey confirms this tendency. Male farmers are seeking various land-leasing, sharecropping and labor arrangements with urban or other patrons to get cash-in-hand to buy food or fertilizers, on the basis of word-of-mouth agreements. They are given immediate cash and/or agricultural inputs in exchange for the later delivery of harvested crops on terms set by the patron. In the process, rural household land access and means of livelihood are being seriously compromised and farmers are being dispossessed of their crop harvests.

In his thought-provoking book, Famine that Kills, de Waal (1989: 227) argued that during the Sudanese famine of 1984/85, farmers in Darfur preferred to go hungry rather than sell off their livestock that they knew would ensure their long-term survival prospects, thereby preserving a material foundation for their continued occupational pursuits as agrarian producers. Furthermore they endeavored to retain community social cohesion.

De Waal's analysis contrasts with our findings in Malawi. Our informants' belief in and commitment to peasant smallholder farming as a livelihood and way of life seems to have experienced serious erosion. This may be because they had always heavily depended on migrant labor that was no longer at hand to support the rural homestead. It may be because of the declining yields they experienced since the removal of the fertilizer subsidy. Furthermore, the weakening of the family labor force due to AIDS encroachment may have played a large part. Most likely all these factors combined to create a state of acute vulnerability, demoralization and defeatism.

Villagers have reached a watershed in terms of the management of their agricultural assets. Given the removal of the fertilizer subsidy and the declining role of ADMARC in marketing, they are giving priority to the day-to-day resolution of hunger through casual labor. Women in the Chimponda focus group discussion told us that all their working time was devoted to 'looking for food'. It was close to harvest time and ripening crops surrounded them but increasingly these crops were not theirs. 'Looking for food' was a euphemism for ganyu. However, no one saw ganyu as a long-term solution. The village headman explained that he discouraged people from ganyu, which he felt only served their immediate needs.

Thus, the villagers no longer had a viable subsistence food production fallback at home, nor sufficient recourse to extended family or external agency assistance. The men were renting out their land for cash-in-hand income and the women were bargaining their labor on casual, highly exploitative terms, leading to an extremely uncertain hand-to-mouth existence. Furthermore, households had reached a highly individualized state whereby they did not dare seek one another's help. Unfortunately, their self-reliance had the net effect of flooding the local labor and factor markets driving down prices and contributing to accelerating impoverishment.

The people in these villages seem not to depend on one another. Each household fends for itself. Their answers [to survey questions] show that in case of material need, their solution is to do piece work rather than beg from fellow villagers or relatives. It seems that there is a general notion that everybody in the village is struggling to survive so no one wants to be a burden on the other. (Observations about Chitukula TA, Gift Hara, survey team leader, 3 March 2004)

The viability of peasant household production and its historical longevity through the millennia in so many places around the world has rested on the combined production of subsistence food and agricultural commodities. This strategy made it possible to counteract the adverse effects of poor food harvests with commodity or labor market sale whereas peasants could react to adverse commodity and labor markets by increasing their reliance on subsistence production. The land and capital constraints faced by Malawian peasants, at present, sets severe limits on any increase of subsistence production as well as offering few commodity production options. Their age-old two-pronged risk-minimizing strategy was failing on both counts. 


\section{HIV Response}

Unlike famine, HIV is a very new threat for Malawian rural households. The AIDS crisis in SubSaharan Africa, as a 'long wave' phenomenon, is barely 25 years old. In 1985 HIV prevalence was 2 percent (Taha et al. 1998). At the time of our study HIV/AIDS prevalence amongst adults 15-49 years of age was estimated at a high 14.4 per cent (Malawi, NAC 2003). Urban adult prevalence is 23 per cent in contrast to rural prevalence of 12.4 per cent. The gap between urban and rural HIV prevalence narrowed during the 1990s from a factor of 5 to 2 . The absolute number of rural dwellers who are $\mathrm{HIV}+$ outnumbers urban HIV+ carriers by roughly three to one.

Coping mechanisms have had very little time to develop. Over the past decade, HIV/AIDS has spread in Malawi against the backdrop of food shortages and depeasantization, devastating local economies and traumatizing communities. These initial years of coping have been accompanied by denial and despair, given the suddenness and extent of the morbidity and mortality experienced. This section reviews the agency of different actors: the traditional leadership, religious bodies, adults and youth.

\section{Traditional Attitudes and Role of Tribal Leaders}

The HIV/AIDS pandemic hit rural Malawi at a time when sexual behavior was undergoing considerable change. Traditionally, sexual behavior was proscribed throughout one's lifetime on the basis of gender and age and these norms were embedded in concepts of community harmony and well-being. There were a variety of sexual taboos considered necessary to optimize conditions for human reproduction and favor with the ancestors, thereby ensuring community harmony. Chiefs as ritual leaders and spiritual heads of the community were the 'essential link in the chain of [community] continuity and fertility' (Boucher 2002 cited by Matinga and McConville 2003).

More secular influences exerted by labor migration and urbanization have no doubt chipped away at these beliefs and the authority of chiefs to enforce them. However, the extent to which chiefs and their rural communities continue to adhere to these beliefs varies widely at present. Remote villages tend towards stronger adherence. However, headmen even in villages close to town continue to see themselves as custodians of village morality that is threatened by the corrupting influence of urban areas, particularly on women.

In my area, cases of sexual immorality are very rare if not non-existent...For example, ever since I became the GVH, I have never handled any cases involving sexual immorality...The problem here is just lack of money and food...In the past, women never used to know town and it was the duty of the husbands to tell them what town looks like... Nowadays, the situation is the opposite. Women know town more than their husbands because they are frequently there to look for food. (Dzama Village Headman interview, 4 December, 2003)

Traditionally sex was perceived as a joyful activity. Men and women had a responsibility to know how to maximize pleasure for their partner and themselves during the sexual act. To this end there were various ritualized extra-marital events that were scheduled throughout one's lifetime which were considered to enhance the quality of one's sexual performance. These included women's sexual cleansing after initiation ceremonies and funerals by a namandwa. In the case of patrilineal societies, chokolo widow inheritance was practiced in many areas. Wives of the deceased were expected to marry one of their husband's brothers. The practice of exchanging wives, chidzeranu, was found in some places. Young virgins, male and female, traditionally were initiated by a trainer (fisi) of the opposite sex who coached them in having sex. Male circumcision was practised although perhaps not as commonly as in many other African countries due to pressure from Christian churches. Furthermore, adolescent girls and boys underwent initiation ceremonies with the chief playing a major role.

The role of the traditional leadership is now crucial to changing sexual attitudes and practices. Enforcement of traditional sexual taboos has been largely in the hands of traditional leaders and is especially the case amongst the Chewa. In recent decades the Chewa's Nyau cult has resurged as a 'secret society' that performs the Gule Wamkule dance as an integral part of Chewa initiation 
ceremonies. Many traditional leaders insist on the continuation of these practices as mechanisms for ensuring cultural awareness and social cohesion.

Most of these practices have, over the decades, been subjected to one or another criticisms by community insiders and outsiders who were relatively educated or had come under the sway of formal religion, especially Christianity. The AIDS crisis has intensified criticism of these practices. However, under Banda, during the 1980s, the initial spread of AIDS was either denied as 'American Invention Depriving Sex' connected with family planning efforts or blamed on western immorality, homosexuality and foreign travel. Malawian traditional culture was held up as a paragon of virtue by the political elite (Lwanda 2002). Currently, as the pendulum swings between traditionalist and modernist perspectives, traditional practices are on the defensive. The Malawian government, slow to act on condom dissemination, changed course during the 1990s and now tries to follow a more Ugandan-like AIDS policy and open discussion of safe sex practices. In so doing many traditional rituals are being re-evaluated by rural dwellers.

The National Aids Commission has been holding training workshops for traditional counsellors in villages aimed at adapting cultural practices to reduce risk. Villagers are now generally aware of the dangers of dirty razors in circumcision ceremonies, sexual cleansers and trainers, and chokolo widow inheritance. Chiefs are increasingly mindful of safety measure stipulations. Circumcisions and other traditional health procedures are now far more likely to be performed with new razor blades and traditional sexual rituals do not occur as much or may be performed with condoms (Shah 2002).

\section{Sexual Attitudes and the Influence of Religion}

In rural Malawi, sex is seen as natural and necessary for survival, illustrated by one male informant's comments that he would not be able to live without sex for more than a week. Certainly it is a vital activity for creative self-expression. Not only is it enjoyable, but in a setting of rural economic decline and lack of promise, sex could be compensatory, a pleasurable escape from the reality of lives availed of little other physical gratification.

The significance of sex in rural Malawi is further demonstrated by the young age at which people start engaging in sex. School teachers and medical personnel confirmed that children begin to be sexually active at the age of 10 or 11 years. Shah (2002) traces this, showing that at this early stage it is usually boys and girls of roughly the same age experimenting with their bodies. Sexual intercourse begins in earnest at about 12-13 for girls and slightly older for boys. Girls are likely to have male sexual partners that are considerably older than them. The risk of HIV/AIDS has led men to favor having sex with adolescent girls. This pattern has been linked to the rising prevalence of HIV amongst younger women.

Combining the everyday 'naturalness' of sex, with the legacy of male circular migration for long-distance labor contracts has introduced the expectation that men not only want but also need to have recourse to extra-marital sex if they are away from their wives for any length of time. This 'fact of life,' however, runs counter to Christianity's insistence on marital fidelity. Evangelical and Pentecostal Christianity have a long history in Malawi (van Dijk 2002). Through radio, the press, and possibly sometimes television, villagers, whatever their religious affiliation, are well aware of marital fidelity as a moral imperative for Christians.

Different media messages are prescribing conflicting sexual behavior. The Christian discourse presents extra-marital behavior as socially unacceptable. Condoms are understood as devices facilitating extra-marital sex that are immoral, a position counter to the widespread efforts of the government and various donor agencies to popularize condom usage. At present, in our study villages, condoms are disregarded by the majority or rural adults as either immoral or abnormal.

\section{Attitudes towards Extra-marital Sex and the Encroachment of Women's Transactional Sex}

Current extra-marital sex within the village was considered to embody both traditional and new aspects.

Generally people like having extra and pre-marital affairs in the village. It is an old culture that looks normal and other people are used to it. (Vizimba Men's FGD 8/12/03) 
There is a bad system of sleeping with each other's wives in this village. Mostly it is the rich men who do this to poor men's wives because it offers them money. The women don't refuse due to their poverty. This is spreading HIV. (Dzama Men's FGD, 4/12/03)

Men, connected with their market activities and recreational drinking habits, frequented pubs to drink and for sexual liaisons.

Men...go to pubs where they sleep with prostitutes who infect them (Dzama Women's FGD, 4 December, 2003).

When men sell their tobacco on the auction floors in Lilongwe they sleep around with lots of women due to the money which they have at that time. Some men go to the extent of seeking temporary marriages elsewhere leaving their families for a little while until all their money is finished. (Vizimba Village Headmen interview, 8 December, 2003).

Women's transactional sex was considered to be an expanding arena of sexual activity that was being increasingly incorporated into ganyu contracts (Shah 2002). This tendency had escalated during the recent famine in response to deepening household impoverishment. Lacking commodities or services to sell, women resorted to the 'essential exchange' of sex for food, travelling to trading centres, Lilongwe and other nearby places to earn cash or food. En-route or at their destinations they encountered economic propositions that sexually compromised them. For example, in Dzama the village closest to Lilongwe, the women had in desperation been going to the grain mill in Area 25 to collect the maize bran that was left after the milling process. This often involved staying overnight on site to get favored access to this resource. Men working at the mill took advantage of this and offered them ganyu contracts. The Dzama Village Action Committee described the phenomena as follows:

We think mostly people are getting infected with HIV/AIDS because of poverty. What usually happens at the household level is that the woman is affected seriously because of her deep concern for her children. She starts looking for ganyu opportunities that are not easy to find in the village so she goes to Area 25 where there are different types of ganyu like cultivating in people's gardens, doing household chores. Some decide just to go to the mill to look for maize bran that they can use for food at home... There they meet men...(Dzama VAC FGD, 4 December, 2003)

Men in the Dzama FGD explained the situation as follows:

The men offer them the ganyu but also entice them to sleep with them. Since the women are bringing food [maize bran], we cannot object [as husbands].

Villagers, both men and women, are increasingly concerned about kusokola, (looking for food), perceived as a famine coping mechanism that leads women into sexual compromise. The Dzama Village AIDS Committee had been researching the nature and extent of kusokola:

We think that 75 percent of the households in this village are fond of this habit of going to Area 25 whilst only 25 percent may be food secure or they just do not want to be involved with doing ganyu in town... When our women go to Area 25 they meet men who are ready to release quick money if they sleep with our women which in most cases they do comply because of the magnitude of their food supply problems and its impact on their families and the suffering of the children. This situation is rampant in months like January when the hunger is at its peak. (Dzama VAC FGD, 4 December, 2003)

It remains to distinguish the 'transactional sex' prevalent currently from 'prostitution'. Prostitution refers to men or women who are occupationally earning their livelihood through the solicitation of sex. They participate in a service market and over time become well-seasoned in the dos and don'ts of economic and physical survival in their occupation. Introducing methods of safer sex to female prostitutes can be relatively straightforward (Campbell 2003) since they have a 
professional interest in adopting safe sex practices and usually are in a position to impose them as a condition of service to their clients. It would be a gross mistake to conflate prostitutes with women practicing transactional sex of an occasional nature. The latter are not professionals earning their livelihood from the sale of sex. Generally they have accidentally happened into sexual encounters and are ill-prepared to bargain the terms of the sexual liaison proposed to them because of the happenchance of the occasion and more fundamentally the compromises they are compelled to make due to their impoverished circumstances. This, together with the diffuse nature of transactional sex, which may happen anywhere anytime, makes safe sex practices very difficult to address.

\section{Community Allocation of Blame for AIDS Mortality}

The first AIDS deaths, experienced in our study villages over ten years ago, and indeed deaths until relatively recently, were mainly men. Now however published HIV prevalence from ante-natal clinics show that HIV prevalence for women is marginally higher than for men. Women's deaths are becoming more frequent with a noticeable increase in deaths of children under-5 years of age as well. The latter are generally not recognized by the villagers as AIDS deaths (Interview with Kasiya Medical Assistant, 8 December 2003). ${ }^{2}$

The AIDS deaths have increased and villagers have taken cognizance of the escalating problem. Not surprisingly when discussing causality villagers tend to point fingers at particular social categories who they believe are spreading AIDS. Women blame men's drinking habits and their enjoyment of sexual liaisons in association with heavy drinking. Men, on the other hand, are increasingly vociferous about women bringing AIDS to the community through their ganyu-earning activities. Both men and women charge that the youth are especially loose these days with their involvement in drinking and casual sex. Youth, while admitting that they are engaged in drinking and sex, blame adults for not setting a good example. The blame game is currently quite good natured, but it is increasingly misogynist in content on the part of frustrated men who have experienced the injury of lost income-earning opportunities over the last couple decades and now insult with their wives' sexual activities for basic needs provisioning. Historically, men earned the household income and women engaged in subsistence farming. It would be hard for men not to feel a sense of failure and resentment towards their wives' current livelihood activities.

\section{Conclusion}

William Allan's (1965) book The African Husbandman offered a penetrating analysis of the riskadversity of tribal peasant agriculture, thoroughly discrediting colonial views on lazy natives and nonmaximizing planting strategies. He argued that farmers aimed at achieving a 'normal surplus' to ensure adequate food for their households in an average year and enough food for survival in a bad harvest year. Inter-cropping of different plants, planting along a soil catena, planting crops at different times throughout the year, and having many different plots all were aimed at averting total crop failure, ensuring some harvest even under the worst climatic conditions. This age-old dictum, however, has increasingly become an unobtainable goal for most smallholder Malawian households subverted by the legacy of male out-migration, over-reliance on maize, declining cultivable plot sizes and the absence of significant technological improvements in staple food yields.

Throughout Sub-Saharan Africa, the last 25 years have been trying for rural smallholders but this is especially so in Malawi during the past five years when the direct impact of the AIDS epidemic and famine have combined to severely undermine household welfare. Malawian smallholder peasant farmers have been experiencing a general trend towards deagrarianization and depeasantization (Bryceson 2002a, 2002b). The peasant household's coherence as a unit of production is collapsing as shifts in household assets and livelihood portfolios have veered: 1) from self-sufficient unpaid labor performed within the household (especially by women and children) towards cash-earning work

\footnotetext{
${ }^{2}$ Statistics on HIV/AIDS prevalence and AIDS mortality rates are extremely problematic. With reference to the former, women's antenatal clinic statistics provide a longer and more reliable record than any data source for male prevalence. AIDS deaths are seriously under-reported given that: 1) medical facilities are grossly inadequate such that most people die at home, and 2) there is a huge stigma about AIDS. AIDS mortality estimates are bound to be rough guesses.
} 
which takes the form of ganyu; 2) from agriculture towards non-agriculture with income-earning turning increasingly to trade and services, including sexual services; and 3) from household towards individualized work, whereby every able-bodied person works including women and youth seek to earn cash to cover their subsistence needs. These are fundamental changes in the nature of peasant household labor patterns. Women and girls are now doing ganyu labor beyond the confines of the village, with demoralizing effects on their menfolk who feel powerless to stop them.

There is a critical difference between depeasantization in Malawi as opposed to its unfolding in most other parts of Sub-Saharan Africa. In Malawi rural income-diversification and depeasantization is going on without the relatively secure subsistence fallback that African smallholder households have so heavily relied upon elsewhere (Bryceson 2002a). Malawian rural dwellers face acute food insecurity because of extremely low agricultural productivity combined with relatively high rural population density and land shortage. The removal of the fertilizer subsidy jeopardized peasant households' subsistence food production further. The majority of households no longer have sufficient land and/or agricultural output to ensure basic household food needs on a yearround basis. Instead they gave priority to off-farm ganyu casual labor over longer-term householdbased cropping cycles to address their immediate food needs causes detrimental seasonal underutilization of household land and labor. A vicious cycle of impoverishment is in progress catapulting more and more into abject poverty, undermining smallholders as a viable agrarian class within the national economy and eroding their well-being and solidarity as village communities.

Qualitative poverty assessments identify food insecurity as the number one indicator of poverty (Malawi, NEC 2002: 15). Village heads in our study estimated that a small minority of welloff households have year-round food self-sufficiency, households occupying the middle stratum have sufficient maize to last five to six months after harvests whereas poor households may be reduced to a month or less of food supplies per year. ${ }^{3}$ Food insecurity, both the extent of its shortfall and its yearby-year repetition, has led Malawian households to severe demoralization. Food security is equated with social respect.

One has to have enough food for people to respect you. A household with no food is not respected. (Women's FGD, Chimponda, 12 March, 2004).

Famine threatens peasant households and village communities in an immediate sense whereas HIV/AIDS threatens individuals and the peasant population in a more long-term insidious way. The imperative of safeguarding against food shortages is deeply embedded in the cultural psyche of the peasant society whereas the AIDS threat, although readily apparent to villagers, is a more recent and seemingly uncontrollable threat. Certainly, we were told time and again that the most fundamental problem faced by the villagers was hunger.

HIV/AIDS is not very threatening compared to the hunger which most households face. In fact it is hunger which is contributing to the rise in HIV infections in the area (Religious leader in Vizimba, 8 December, 2003).

Transactional sex through women's ganyu labor contracts risks death to alleviate hunger. The question of agency - who is making the decision and why - goes beyond the question of what social, political and economic processes increase the likelihood of HIV infection. Risk assessment involves knowledge and the capability to choose by weighing the odds and acting on them. In this case, the Malawian peasantry, specifically peasant women, are consciously buying time. In the face of an end game of declining assets, income, and food security, they forestall death by engaging in what could be termed the most essential exchange: sex for food.

\footnotetext{
${ }^{3}$ In a survey of rural households in Central Province during the famine year of $2001: 72 \%$ of households harvested maize sufficient to last only 3 months, 15\% 3-6 months, 6\% 6-9 months and a mere 7\% more than 9 months. Less than 5\% were self-sufficient in maize (Ellis et al. 2003).
} 


\section{Bibliography}

Alison, E. and J. Seeley 2004, 'HIV and AIDS among Fisherfolk: A Threat to "Responsible Fisheries"?', Fish and Fisheries 5, 215-34

Allan, W. 1965, The African Husbandman, London, Oliver \& Boyd

Bookstein, A. and M. Lawson 2002, 'Briefing: Famine in Southern Africa', African Affairs 101, 63541.

Boserup, E. 1989 (orig 1970), Woman's Role in Economic Development, London, Earthscan Publications Ltd.

Boucher Chisale, Fr. C. 2002, The Gospel Seed: Culture and Faith in Malawi, Mua Mission Bryceson, D.F. 1995, Women Wielding the Hoe, Berg Publishers, Oxford

Bryceson, D.F. 2000, 'African Peasants' Centrality and Marginality: Rural Labor Transformations', in Bryceson, D.F., C. Kay and J. Mooij (eds), Disappearing Peasantries: Rural Labor in Africa, Asia and Latin America, London, Intermediate Technology Publications

Bryceson, D.F. 2002a, 'The Scramble in Africa: Reorienting Rural Livelihoods', World Development $30(5), 725-39$

Bryceson, D.F. 2002b, 'Multiplex Livelihoods in Rural Africa: Recasting the Terms and Conditions of Gainful Employment', Journal of Modern African Studies 40 (1), 1-28

Bryceson, D.F. 2002c, 'Pleasure and Pain: The Ambiguity of Alcohol in Africa', in Bryceson, D.F. (ed.), Alcohol in Africa: Mixing Business, Pleasure and Politics, Portsmouth, NH, Heinemann

Campbell, C. 2003, 'Letting Them Die': Why HIV/AIDS Prevention Programmes Fail, Oxford, James Currey

de Waal, A. and A. Whiteside 2003, "New Variant Famine": AIDS and Food Crisis in Southern Africa', The Lancet 362: 1234-37

de Waal, A. 1989, Famine that Kills: Darfur, Sudan, 1984-85, Oxford, Clarendon Press

Ellis, F., M. Kutengule and A. Nyasulu 2003, 'Livelihoods and Rural Poverty Reduction in Malawi', World Development 31 (9): 1495-1510.

Ellis, F. and H.A. Freeman 2005, 'Comparative Evidence from Four African Countries', in Ellis, F. and H.A. Freeman, Rural Livelihoods and Poverty Reduction Policies, London, Routledge, $31-47$

Englund, H. 1999, 'The Self in Self-Interest: Land, Labor and Temporalities in Malawi's Agrarian Change', Africa 69 (1), 139-59

Frankenberger, T., K. Luther, K. Fox and J. Mazzeo 2003, 'Livelihood Erosion through Time: Macro and Micro Factors that Influenced Livelihood Trends in Malawi over the Last 30 Years', TANGO International, Inc., CARE Southern and Western Africa Regional Management Unit (SWARMU), March 2003

Lwanda, J. 2002, 'Tikutha: The Political Culture of the HIV/AIDS Epidemic in Malawi', in Englund, H. (ed.) A Democracy of Chameleons: Politics and Culture in the New Malawi, Stockholm, Nordiska Afrikainstutet

Malawi, Government of 2002, Malawi National Land Policy, Lilongwe, Ministry of Lands, Physical Planning and Survey

Malawi, NAC, 2003, HIV prevalence and AIDS mortality statistics

Malawi, NEC 2002, Qualitative Impact Monitoring (QIM) of the Poverty Alleviation Policies and Programmes in Malawi, Volume 1: Survey Findings, Lilongwe

Matinga, P. and F. McConville 2003, 'A Review of Cultural Beliefs and Practices Influencing Sexual and Reproductive Health, and Health-seeking Behaviour, in Malawi', DFID Malawi, July 2003

Ngwira, N., S. Bota and M. Loevinsohn 2001, 'HIV?AIDS, Agriculture and Food Security in Malawi', Lilongwe and The Hague, Regional Network on HIV/AIDS Rural Livelihoods and Food Insecurity (RENEWAL) Working Paper 1

Peters, P.E. 1996, 'Failed Magic or Social Context? Market Liberalization and the Rural Poor in Malawi', Cambridge USA, HIID Development Discussion Paper

Schoffeleers, J.M. 1985, Pentecostalism and Neo-Traditionalism: The Religious Polarization of a Rural District in Southern Malawi, Amsterdam, Free University Press 
Shah, M.K. 2002, 'Buying Sex for Three Sweet Potatoes: Participatory Assessment of Adolescent Sexual and Reproductive Health in Makala Village, Lilongwe', CARE International Consultancy Report, August 2002

Taha, T.E., G. Dallabeta, J.D. Chiphangwi, L.A.R. Mtimavalye, N.G. Liomba, N. Kumwenda, D. Hoover and P. Miotti 1998, 'Trends of HIV-1 and Sexually Transmitted Diseases among Pregnant and Postpartum Women in Urban Malawi', unpublished MS, copy at college of Medicine Library, Blantyre

UNAIDS 2004, http:://www.unaids.org/Unaids/EN/Geographical+area/ByCountry/ Malawi.asp van Dijk, R. 2002, 'Modernity's Limits: Pentecostalism and the Moral Rejection of Alcohol in Malawi', in Bryceson, D.F. (ed.), Alcohol in Africa: Mixing Business, Pleasure and Politics, Portsmouth, NH, Heinemann

Vaughan, M. 1987, The Story of an African Famine: Gender and Famine in Twentieth Century Malawi, Cambridge University Press 